\title{
The GEF/UNDP/UNIDO Global Mercury Project - Environmental and Health Results from a Small- Scale Gold Mining Site in Tanzania
}

\author{
Appleton D, Drasch G, Böese-O'Reilly S, Roider G, Lister R, Taylor H, Smith B, Tesha A, and Beinhoff C.
}

\section{Introduction}

Artisanal gold mining is one of the major sources of mercury contamination, especially in developing countries. Whilst the gold extraction process (known as amalgamation) is a simple technology, it is potentially very harmful to the environment and can contaminate air, soil, rivers and lakes with mercury. The health of the miners and other people living within the area affected by mercury contamination may be negatively affected through inhalation of mercury vapour or contaminated dusts, direct contact with mercury, through eating fish and other food, and through the ingestion of waters and soils affected by the mercury contamination.

Environmental and health impacts resulting from the use of mercury (Hg) in the artisanal gold extraction process require concerted and coordinated global responses. The objective of the ongoing GEF/UNDP/UNIDO project Removal of Barriers to the Introduction of Cleaner Artisanal Gold Mining and Extraction Technologies (also referred to as the Global Mercury Project (GMP)) in Brazil, Indonesia, Lao PDR, Sudan, Tanzania, and Zimbabwe is to assist these countries located in key transboundary river/lake/marine basins in assessing the extent of $\mathrm{Hg}$ pollution, introducing cleaner gold extraction technology, which eliminates or reduces $\mathrm{Hg}$ releases and developing capacity and regulatory mechanisms. The GMP Project is accompanied by the development of monitoring programmes. In order to ensure sustainability, capacity is being built to carry out continuous monitoring beyond the project three-year term. The ultimate goals of the GMP Project are:

1. to reduce Hg pollution of international waters by emissions emanating from small-scale gold mining;

2. to introduce cleaner technologies for gold extraction and to train people in their application;

3. to develop capacity and regulatory mechanisms that will enable the sector to minimize mercury pollution;

4. to introduce environmental and health monitoring programmes;

5. to build capacity of local laboratories to assess the extent and impact of Hg pollution.

The GMP Project will also aim to increase knowledge and awareness of miners, Government institutions and the public at large by explaining in detail the results of the Public Health and environmental studies conducted in the mercury "hot spot" areas.

The selection of project demonstration sites was done in accordance with the objective of alleviating the impact of Hg on international waters. Two sites were selected in Brazil (Creporizinho and Sao Chico in the Tapajos area draining into the Amazon river) and Indonesia (Galangan mine in Central Kalimantan, draining into the Java Sea and Talawan near Manado, draining into the Celebes Sea). One demonstration site was selected in each of the other four countries: Lao PDR (Luang Prabang, draining into the Mekong river), Sudan (Gugob, near Al Damzain, draining into the Blue Nile), Tanzania (Rwamagasa, draining into Lake Tanganyika) and Zimbabwe (Chakari, draining to a tributary of the Zambezi river).

In August 2003, the British Geological Survey (BGS), acting under the UK Natural Environment Research Council, signed a contract with UNIDO to carry out limited Environmental and Health surveys and assessments in the Rwamagasa artisanal gold mining area in the Republic of Tanzania (Appleton et al., 2004). The environmental assessment was executed by the BGS whilst the medical and toxicological investigations were subcontracted to the Institut für Rechtsmedizin der Ludwig-Maximilians-Universität München, Germany. The regional health authorities in Geita supported the medical investigations, whilst the environmental assessment was carried out in collaboration with staff from the Geita Mines Office and from the Kigoma and Mwanza offices of the Tanzania Fisheries Research Institute (TAFIRI).

Rwamagasa is located in Geita District, which has an area of 7,825 km², 185 villages, and a population around 712,000 (census of 2002). The number of artisanal miners in the Geita District is unknown but it is estimated to be as many as 150,000 , most of whom are illegal panners. Primary artisanal workings in the 
Rwamagasa area are centred on quartz veins in sheared, ferruginous, chlorite mica schists. Grab samples of vein and wall rock grade 6-62 g/t Au. The only legal mining in the Rwamagasa area is carried out within the boundaries of the Primary Mining Licence held by Blue Reef Mines where approximately 150 people are involved in mining and mineral processing activities. This is the only site in the Rwamagasa area where primary ore is being mined underground. All other mineral processing activity of any significance is concentrated at the northern margin of Rwamagasa, especially on the land sloping down to the Isingile River. In this area, there are about 30 groups of historic and active tailings dumps and about ten localities where small (200 litre) ball mills are operating. The number of people actively involved, at one particular time, in ball milling, sluicing and amalgamation is probably no more than 300 .

Amalgam is burned in a small charcoal fire, which releases $\mathrm{Hg}$ to the atmosphere. Amalgamation mainly takes place adjacent to amalgamation ponds, which are usually formed of concrete, but sometimes have only wood walls even though environmental legislation dictates that the $\mathrm{Hg}$ contaminated mineral concentrates and tailings should be stored in concrete lined structures.

The Blue Reef Mine is reported to produce about $1 \mathrm{~kg}$ Au per month whereas artisanal miners re-working tailings produce about $0.5 \mathrm{~kg}$ per month. On this basis, approximately $27 \mathrm{~kg}$ of $\mathrm{Hg}$ will be released to the environment from the Rwamagasa area each year. Of this, atmospheric emissions from amalgam burning will be about $14 \mathrm{~kg}$ from the Blue Reef mine site and $7 \mathrm{~kg}$ from the other amalgamation sites. About 2 to 3 $\mathrm{kg} \mathrm{Hg}$ will remain in heavy mineral tailings in the amalgamation ponds, which are frequently reprocessed. It is reported that the number of miners working in the Rwamagasa area was much larger in the past, so the historical release of mercury would probably have been higher than at present.

The young and strong men, so called healthy workers, are mainly found in the bigger and more technically equipped properties. Older people, women of all ages and children mainly work in the smaller artisanal mining properties. Retorts are not used, neither is there any other protection, such as ventilation, against any kind of mercury contamination. Housing areas, food stalls and the schools are located close to the sites where amalgamation and burning of the amalgam is carried out. Mineral processing tailings containing mercury are found within the village adjacent to cultivated land or near local water wells. Mercury is usually stored in the miner's houses in small soft-drink bottles, near to where they and their families sleep. The mercury is mainly obtained from Nairobi in Kenya and the gold is either used for jewellery in Tanzania or sold to Dubai.

Hygiene standards are extremely low and are a reason for many infectious diseases such as diarrhoea, typhoid and parasitism. There is no effective waste disposal system for either mercury, sanitary or other domestic waste.

Road accidents, accidents in insecure tunnels and amalgamation plants, malaria, tuberculosis, and sexually transmitted diseases including AIDS are the dominant causes of morbidity and mortality. No special health service exists for the mining community - the nearest dispensary is about $10 \mathrm{~km}$ away. A local dispensary is under construction, but the construction has been stopped due to lack of money. The village lacks social welfare services and a police post for security. The nearest district hospital is in Geita, $45 \mathrm{~km}$ to the northeast. All non-minor illnesses have to be transferred to Geita hospital, which is adequately equipped for a district hospital.

Background information on mercury contamination associated with artisanal gold mining in Tanzania is available in a number of published reports and scientific papers (Appel et al., 2000; Asanao et al., 2000; Campbell et al., 2003a,b; Harada et al., 1999; Ikingura and Akagi, 1996; Ikingura et al., 1997; Ikingura and Akagi, 2002; Kahatano et al., 1997; Kinabo, 1996; Kinabo, 2002a,b; Kinabo and Lyimo, 2002; Kishe and Machiwa, 2003; Machiwa et al., 2003; Mutakyhwa, 2002; Semu et al., 1989; Sindayigaya, 1994; University of Dar es Salaam, 1994; van Straaten 2000a,b).

\section{Environmental assessment field programme}

The objective of the environmental assessment was to (i) identify hotspots in the project demonstration sites, (ii) conduct specified geochemical and toxicological studies and other field investigations in order to assess the extent of environmental pollution in surrounding water bodies and (iii) devise intervention measures. Although Rwamagasa is located only $37 \mathrm{~km}$ to the south of Lake Victoria, streams draining the Rwamagasa 'mining hotspot' actually drain SW into the Nikonga River, and then for a further $430 \mathrm{~km}$ via the Moyowosi swamps and the River Malagarasi before reaching Lake Tanganyika near Ilagala, about $50 \mathrm{~km}$ to the SSE of Kigoma. One of the major objectives of the project is to assess the impact of mercury contamination on 
international waters as well as in the vicinity of the 'mining hotspot', so the field programme was carried out in two areas: (a) the Rwamagasa 'mining hotspot' sub-area and (b) the Lake Tanganyika - River Malagarasi sub-area (see Figure 1). Dispersion of $\mathrm{Hg}$ from Rwamagasa to Lake Tanganyika is probably relatively unlikely because contaminant $\mathrm{Hg}$ will be adsorbed by organic material in the extensive Moyowozi and Njingwe Swamps and flooded grassland area, located from $120 \mathrm{~km}$ to $350 \mathrm{~km}$ downstream of Rwamagasa. Whereas the swamps will act as a potential biomethylation zone, they will also act as an environmental sink for $\mathrm{Hg}$ contamination, which is likely to inhibit migration of $\mathrm{Hg}$ into the lower reaches of the Malagarasi River and Lake Tanganyika. The swamp area was inaccessible within the logistical and budgetary constraints of the current project.

The environmental field programme was carried out during the dry season at which time there was little evidence that large quantities of contaminated tailings were being washed into the Isingile River. However, waste water and tailings from amalgamation 'ponds' were observed at one site to be overflowing onto an area where vegetables were being grown. If large quantities of $\mathrm{Hg}$ contaminated tailings are dispersed onto the seasonal swamp (mbuga) area adjacent to the Isingile River during the wet season, then this may lead to the significant dispersion of $\mathrm{Hg}$ both into the aquatic system and onto agricultural sites being used for rice, maize, and vegetable cultivation.

Previous studies in the Lake Victoria Goldfields area indicate that dispersion of Hg from tailings is relatively restricted, not least because Fe-rich laterites and seasonal swamps (mbugas) act as natural barriers or sinks attenuating the widespread dispersion of $\mathrm{Hg}$ in sediments and soils.

A field programme was carried out in September-October 2003 leading to the collection of a total of 38 water, 26 drainage sediment, 151 soil, 66 tailings, 21 vegetable and 285 fish samples. Preparation and analysis of the samples was carried out in the UK and Canada. Analytical data for duplicate field samples, replicate analyses and recovery data for Certified Reference Materials indicate a level of analytical precision and accuracy that is appropriate for this type of environmental survey. $\mathrm{Cd}, \mathrm{Cu}, \mathrm{Pb}$ and $\mathrm{Zn}$ were determined in drainage sediment, tailings and soil samples, in addition to $\mathrm{Hg}$ and As (which were specified in the ToR and BGS's proposal) on the basis that these could be useful indicators of mineralization and/or anthropogenic contamination. The range of chemical substances determined in the samples collected, and the range of media sampled should not be considered to represent a comprehensive environmental survey. In addition, the results reported here refer only to the sites sampled at the time of the survey and should not be extrapolated to infer that elevated levels of contamination are not present at other sites or elsewhere in the district or region. The results presented reflect the level of resources available for the environmental assessment.

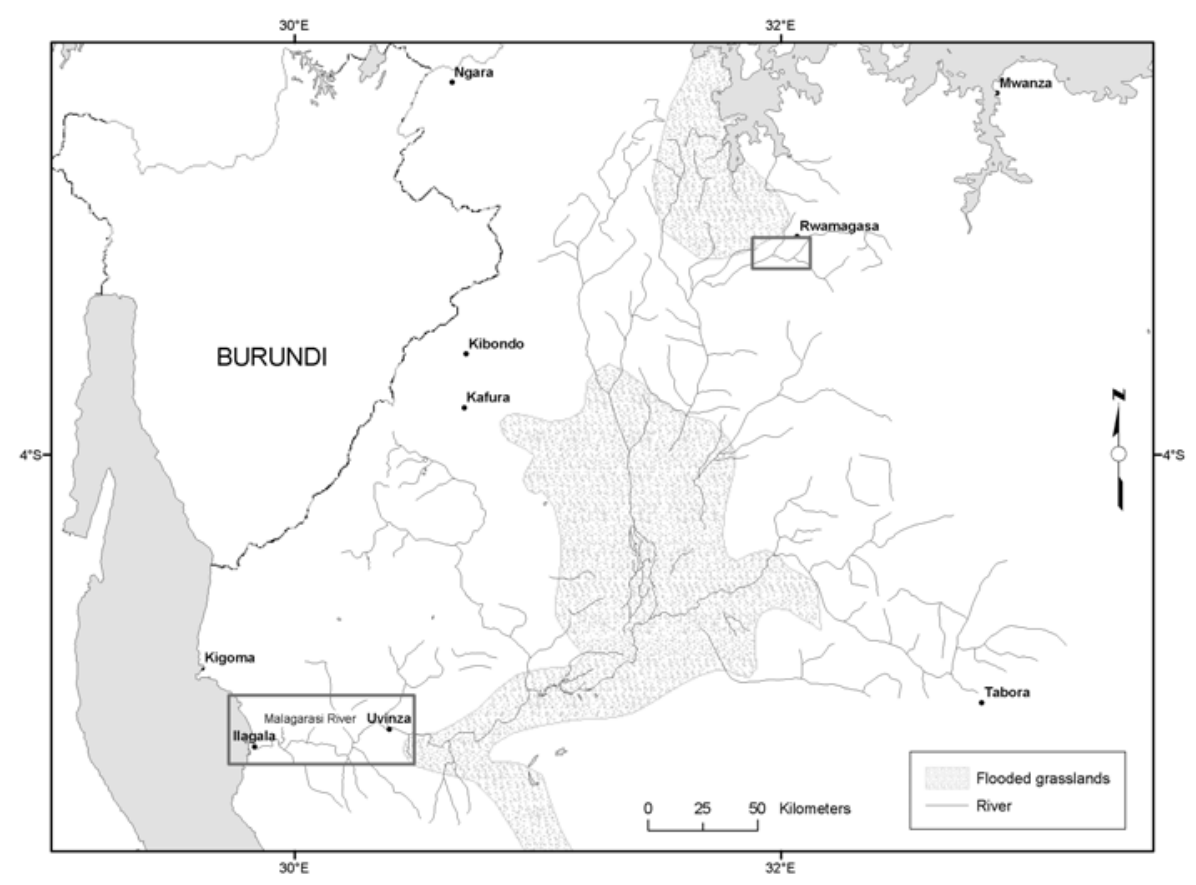

Figure 1. Location of the River Malagarasi and Rwamagasa sub-areas in northwest Tanzania. 


\section{Nature and extent of the mercury pollution in the river system}

At the time of sampling, mercury in filtered drainage water samples ranged from 0.01 to $0.03 \mu \mathrm{g} / \mathrm{L}$ in the R. Malagarasi and from 0.01 to $0.07 \mu \mathrm{g} / \mathrm{L}$ in the Rwamagasa area. None of the filtered water samples exceeded any of the Tanzanian Water Quality Standards or other national and international water quality standards, or criteria for drinking water, protection of aquatic biota or the protection of human health. Arsenic in filtered water ranged from 0.1 to $2.4 \mu \mathrm{g} / \mathrm{L}$ and none of the samples collected exceeded any water quality standards or criteria.

Hg concentrations in the fine fraction of streams sediments from the River Malagarasi at Ilagala range up to $0.65 \mathrm{mg} / \mathrm{kg}$, which is rather high for an area that does not appear to be unduly affected by anthropogenic contamination. Concentration of $\mathrm{Hg}$ in the fine fraction, together with adsorption of $\mathrm{Hg}$ onto $\mathrm{Fe}$ and organic material, may in part explain these relatively enhanced $\mathrm{Hg}$ concentrations, but these hypotheses need to be verified by further studies. Other possible sources include the geothermal springs at Uvinza or contamination of sediment by mercuric soap, which may be used by some people for skin lightening, although no evidence of this was observed during the field programmes. (but we/Stephan didn't see any evidence of skin lightening)

In the Rwamagasa area, $\mathrm{Hg}$ in the fine fraction of drainage sediments ranges from 0.08 to $2.84 \mathrm{mg} / \mathrm{kg}$, although $\mathrm{Hg}$ does not exceed the Toxic Effects Threshold $(1 \mathrm{mg} \mathrm{Hg} / \mathrm{kg}$ ) of the Canadian Sediment Quality Criteria for the Protection of Aquatic Life for more than $2 \mathrm{~km}$ downstream from the major mineral processing centre located to the south of the Isingile River. Toxic Effects Thresholds for $\mathrm{As}, \mathrm{Cd}, \mathrm{Cu}, \mathrm{Pb}$ and $\mathrm{Zn}$ are not exceeded in drainage sediments from the Rwamagasa area.

\section{Environmental assessment of the Rwamagasa area based on sampling of mineral processing wastes and soils}

There is little difference between Hg concentrations in samples taken from historic (dry) primary tailings piles (mean $5 \mathrm{mg} / \mathrm{kg}$ ) and samples taken from recent sluice box tailings (mean $3 \mathrm{mg} / \mathrm{kg}$ ). $\mathrm{Hg}$ in tailings samples from the amalgamation ponds and amalgamation pond tailings (mean $86 \mathrm{mg} / \mathrm{kg}$ ) are on average about 20 times higher. The high level of $\mathrm{Hg}$ in the primary and sluice box tailings is the result of recycling/reprocessing of amalgamation pond tailings. An association between $\mathrm{Cd}-\mathrm{Cu}-\mathrm{Hg}-\mathrm{Zn}$ probably reflects contamination from mercury used in amalgamation combined with metals that are possibly derived from the ball mills and galvanised roof sheets. Correlations between arsenic and iron probably reflect the influence of trace quantities of arsenopyrite and pyrite in the gold ore. Both these hypotheses need to be verified.

At the time of the survey, generally low concentrations of Hg occurred in most of the analyzed soils used for cassava, maize, and rice cultivation, as well as mbuga and unclassified soils located away from the urban centre of Rwamagasa and associated mineral processing areas. Higher concentrations are found in urban soils and also in mbuga and vegetable plot soils adjacent to the Isingile River, close to the mineral processing areas. $\mathrm{Hg}$ in the urban soils is probably mainly derived from air borne transport and deposition of $\mathrm{Hg}$ released during the burning of amalgam, although this has not been verified. High Hg appears to occur in the mbuga and vegetable plot soils where these are impacted by Hg-contaminated water and sediment derived from mineral processing activities located on the southern side of the Isingile River. In these soils there is a clear association between $\mathrm{Cd}-\mathrm{Cu}-\mathrm{Zn}$, which reflects contamination from metals that are possibly derived from the ball mills and/or galvanized roof sheets. An association between $\mathrm{As}$, $\mathrm{Cu}$ and Fe probably reflects the influence of the weathering products of arsenopyrite and pyrite found in the gold ore, although this needs to be verified.

Mercury exceeds (1) the maximum permissible concentration of $\mathrm{Hg}$ in agricultural soil in the UK (1 mg/kg) in 12 soil samples; (2) the Canadian Soil Quality Guideline for agricultural soils $(6.6 \mathrm{mg} / \mathrm{kg})$ in three samples; and (3) the UK soil guideline value for inorganic Hg for allotments (8 mg/kg) in two samples.

Cadmium and zinc exceed the maximum permissible concentrations for agricultural soil in the UK (3 mg $\mathrm{Cd} / \mathrm{kg}$ and $200 \mathrm{mg} \mathrm{Zn/kg)} \mathrm{in} \mathrm{only} \mathrm{a} \mathrm{few} \mathrm{soil} \mathrm{samples.} \mathrm{Arsenic} \mathrm{exceeds} \mathrm{the} \mathrm{Canadian} \mathrm{Soil} \mathrm{Quality} \mathrm{Guideline}$ for agricultural soils $(12 \mathrm{mg} / \mathrm{kg})$ in nine agricultural and urban soils. 
Soil profile data demonstrate that surface contamination by mineral processing waste in some agricultural soils affects the root zone. Hoeing of the soils is likely to result in mixing of surface $\mathrm{Hg}$ contamination throughout the root zone, although this has not been verified.

\section{Mercury in agricultural produce}

$\mathrm{Hg}$ in vegetable and grains samples collected from the agricultural areas potentially impacted by mercury contamination are mainly below the detection limit of $0.004 \mathrm{mg} / \mathrm{kg} \mathrm{Hg}$ with concentrations of 0.007 and $0.092 \mathrm{mg} / \mathrm{kg} \mathrm{Hg}$ recorded in two yam samples and $0.035 \mathrm{mg} / \mathrm{kg} \mathrm{Hg}$ in one rice sample. A positive correlation between $\mathrm{Hg}$ in agricultural crops and soil was not detected during the present survey. Hg in beans, onions and maize samples purchased at Rwamagasa market are below the detection limit $(<0.004 \mathrm{mg} \mathrm{Hg} / \mathrm{kg})$ whilst two dehusked rice samples contain 0.011 and $0.131 \mathrm{mg} / \mathrm{kg} \mathrm{Hg}$. The concentrations of $\mathrm{Hg}$ in rice are similar to those recorded in rice grown on the highly contaminated soils of the Naboc irrigation system on the island of Mindanao in the Philippines.

\section{Mercury in fish: biomarkers for mercury methylation and potential food sources}

The main fish species used as bioindicators of mercury contamination included perch (Lates spp), tigerfish (Brycinus spp), tilapia (Oreochromis spp), catfish (Clarias spp). Fish tissue THg data indicates that the sites sampled in the immediate area of mining activities at Rwamagasa, are the worst affected (Figure 2) and should be considered environmental 'hotspots' and sites of biomethylation. Many fish tissue samples from these sites fail export market standards $(0.5 \mathrm{mg} / \mathrm{kg})$ and also exceed the WHO recommended standard for the protection of health of vulnerable groups $(0.2 \mathrm{mg} / \mathrm{kg})$. Mercury in fish collected from the Nikonga River, approximately $25 \mathrm{~km}$ downstream from Rwamagasa, have low $\mathrm{Hg}$ concentrations. This suggests that the impact of mercury contamination on aquatic biota is relatively restricted, which is confirmed by the generally low mercury concentrations in drainage sediment and mbuga soils at distances more than about 6 $\mathrm{km}$ downstream of the main mineral processing area (or 'hotspot'). However, this observation will need to be verified by more detailed studies.

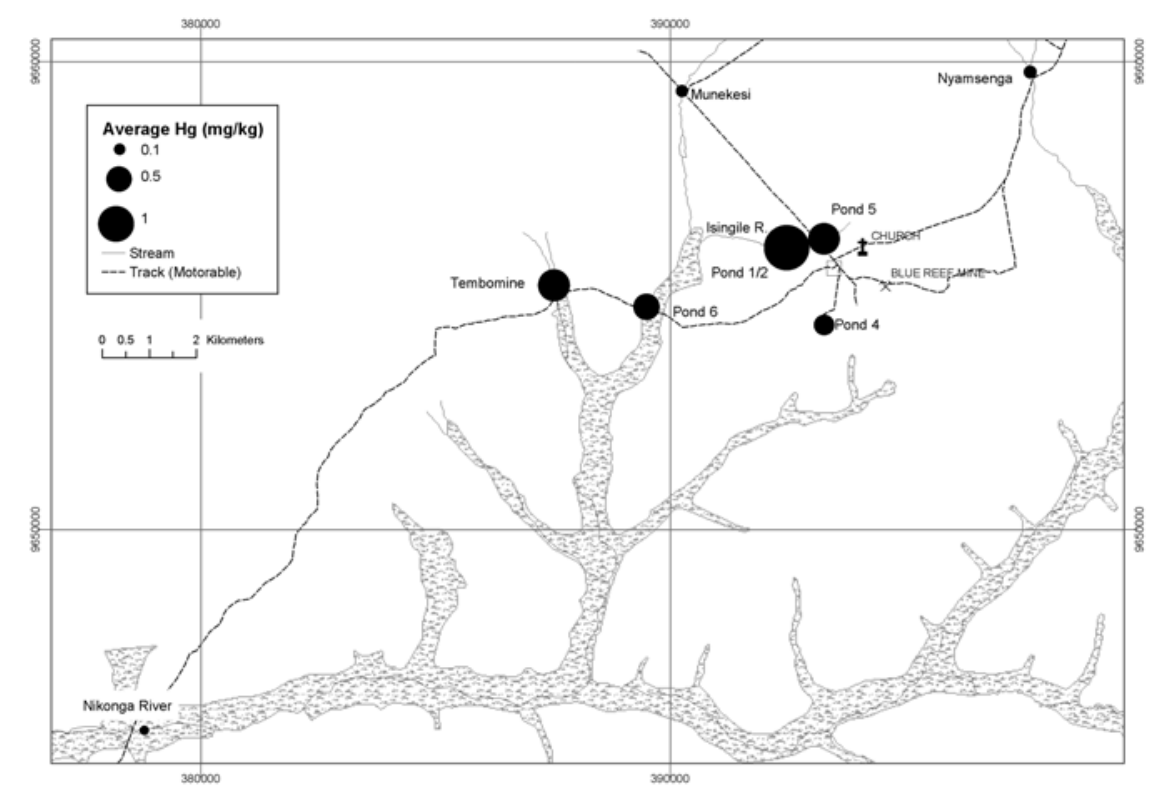

Figure 2. Average mercury concentration (mg/kg) in catfish (Clarias spp.), Rwamagasa area.

Fish length vs. mercury concentration plots for fish from the River Malagarasi and Malagarasi delta area of Lake Tanganyika (collected from Uvinza and Ilagala) confirm generally low mercury concentrations that are similar to levels found in similar species in Lake Victoria (Figure 3). All fish samples collected from the Malagarasi River area are below the WHO threshold for vulnerable groups $(0.2 \mathrm{mg} / \mathrm{kg})$. This suggests that mercury contamination from the Rwamagasa artisanal gold mining centre does not have a significant impact 
on fish stocks in either the lower reaches of the River Malagarasi or the international waters of Lake Tanzania.

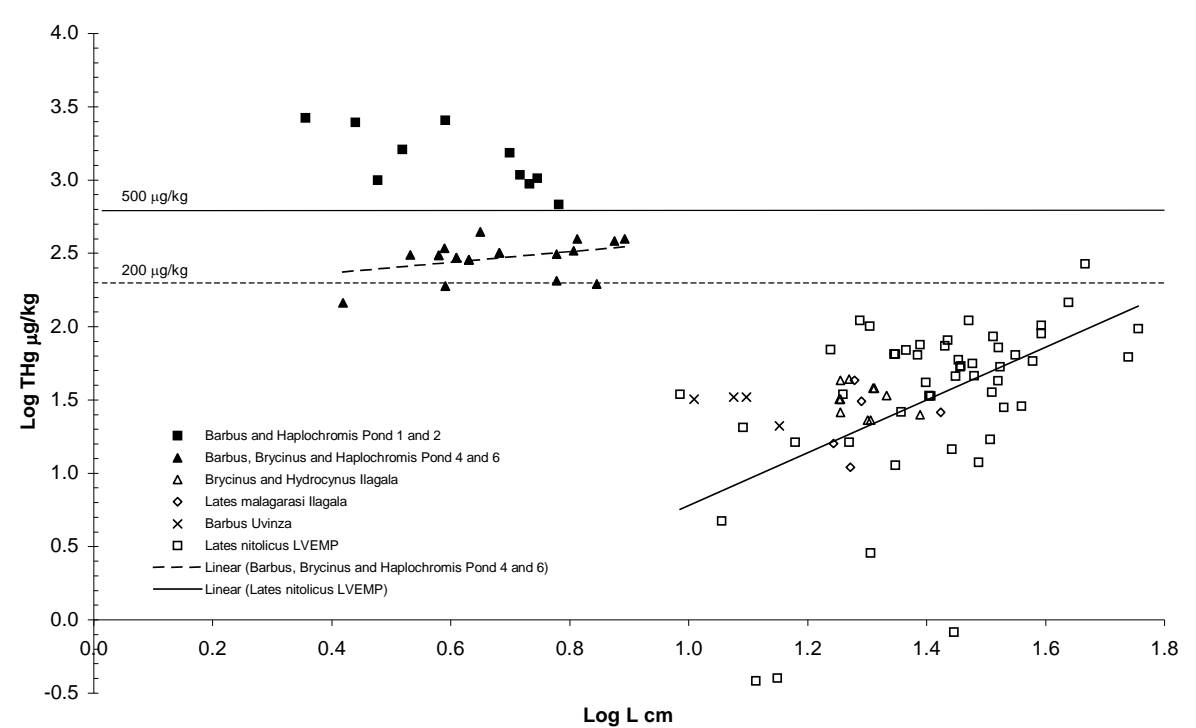

Figure $3 \mathrm{Hg}(\mu \mathrm{g} / \mathrm{kg}$ ) related to length $(\mathrm{cm})$ in piscivorous, insectivorous and planktivorous fish from (a) the Rwamagasa area, (b) River Malagarasi - Lake Tanganyika (Ilagala, Uvinza) and (c) Lake Victoria (Lake Victoria Environmental Management Project, Machiwa et al. 2003).

\section{Exposure to environmental mercury}

None of the water samples collected from the river network, or associated drainage ponds exceeded the WHO or local Tanzanian guideline values of $1 \mu \mathrm{g} \mathrm{Hg} / \mathrm{l}$ for drinking water. Whilst this suggests that mineral processing operations have not contaminated local surface waters and shallow groundwaters it does not indicate whether drinking water used by the local people has been contaminated with $\mathrm{Hg}$ or other non-related substances. More extensive monitoring of drinking water sources (which was not the focus of the current investigations) should be considered as a component of any subsequent follow up work.

The only samples of filtered water collected during the survey that contained relatively high $\mathrm{Hg}$ concentrations (max. $0.45 \mu \mathrm{g} \mathrm{Hg/l)}$ were from amalgamation ponds. This highlights the need for careful management of waste-waters from these ponds and monitoring of any nearby drinking water supplies.

The average mercury concentration recorded for samples of rice grain grown on soils potentially impacted by mercury contamination was $0.026 \mu \mathrm{g} / \mathrm{g}$ (dry wt.). Consequently, the amount of mercury entering the body, assuming an average consumption of $300 \mathrm{~g}$ rice/day is $0.055 \mathrm{mg} \mathrm{THg} /$ week (equivalent to $0.46 \mu \mathrm{gg} \mathrm{MeHg} / \mathrm{kg}$ bw/week), which is much lower than the Provisional Tolerable Weekly Intake (PTWI) of $0.3 \mathrm{mg}$ for total mercury and $1.6 \mu \mathrm{g} / \mathrm{kg}$ bw/week for methyl mercury (MeHg) in the diet set by the WHO and the FAO. These are likely to maximum inputs because most people in the Rwamagasa area will consume less than $300 \mathrm{~g}$ rice/day because they will also consume cassava and maize, which are generally grown on soils with low Hg. This observation needs to be verified by more detailed studies.

The vast majority of people in the Rwamagasa area principally eat Tilapia (Oreochromis spp.), Perch (Lates spp.) and dagaa (dagan; Rastrineobola spp. and equivalents) from Lake Victoria. Catfish (Clarias spp; kamare, mumi) is eaten by less than $10 \%$ of those people. Consumption of $250 \mathrm{~g}$ perch, $500 \mathrm{~g}$ tilapia and $250 \mathrm{~g}$ of catfish each week would result in an intake of $27 \mu \mathrm{g}$ THg/week (equivalent to $0.35 \mu \mathrm{g} \mathrm{MeHg} / \mathrm{kg}$ bw/week) for residents of Ilagala-Uvinza area, $44 \mu \mathrm{g} \mathrm{THg} /$ week (equivalent to $0.58 \mu \mathrm{g} \mathrm{MeHg} / \mathrm{kg}$ bw/week) for Rwamagasa residents consuming only fish from Lake Victoria, $56 \mu \mathrm{g} \mathrm{THg} /$ week (equivalent to $0.75 \mu \mathrm{g}$ $\mathrm{MeHg} / \mathrm{kg}$ bw/week) for people in the Rwamagasa background area consuming tilapia and perch from Lake Victoria and catfish from the local streams, and $259 \mu \mathrm{g} \mathrm{THg} / \mathrm{week}$ (equivalent to $3.45 \mu \mathrm{g} \mathrm{MeHg} / \mathrm{kg}$ bw/week) for people in the Rwamagasa area consuming tilapia and perch from Lake Victoria and catfish from mining impacted streams. Apart from the latter group, these inputs related to fish consumption are well below the WHO/FAO PTWI . It appears that only those people consuming catfish from the Isingile River, 
and other mining contaminated locations such as Tembomine, are likely to be at risk of exceeding the PTWI for Hg.

People consuming 300g/day of rice grown on the Hg contaminated Isingile mbuga soils and $1 \mathrm{~kg}$ of fish from Lake Victoria would have a combined estimated MeHg input of $1.04 \mu \mathrm{geHg} \mathrm{kg}$ bw/week, which is two thirds of the MeHg PTWI.

Whereas it is not known whether individuals practice geophagia in the Rwamagasa area, elevated exposures to Hg could result from the occasional deliberate and habitual consumption of contaminated soils and dusts. For example, the PTWI of $0.3 \mathrm{mg}$ for total $\mathrm{Hg}$ in the diet set by the WHO and the FAO, is equivalent to 26 $\mu \mathrm{g} \mathrm{THg} /$ day for a $30 \mathrm{~kg}$ child and would be exceeded by an individual practising geophagia (central estimate and worst-case) or on a case by case basis by an individual occasionally consuming soil/dust (worst-case). The practice of geophagy by pregnant females would be of particular concern in this regard given the sensitivity of the foetus to $\mathrm{Hg}$.

The inadvertent ingestion of dusts and soils even those having Hg concentrations significantly above the regional background, and hence considered to be moderately contaminated, does not appear to lead to a significant excess exposure to Hg. For comparison, exposures due to inadvertent ingestion of soils and/or dusts ( 0.72 to $1.8 \mu \mathrm{g} \mathrm{THg} / \mathrm{day}$ or 5 to $13 \mu \mathrm{g}$ THg/week) are typically less than individual exposure via other dietary sources water, rice and fish.

However, given the uncertainties involved in estimating inadvertent dust and soil intake in the rural Rwamagasa environment, exposure via this route, in addition to more classical geophagic behaviour, should be considered when planning remedial/intervention measures. Such measures could include the marking and fencing off of waste tips and areas of enhanced contamination and improvements in hygiene (washing of hands and food preparation such as the drying of cassava and other crops directly on the ground and the use of soil as a desiccant to aid the storage of groundnuts and beans). Whilst geophagy does have an important cultural and possibly nutritional benefit, the resulting levels of potential exposure to young adults and pregnant woman are high enough to suggest that this practice should be positively discouraged within the mining districts. If it was demonstrated that geophagy is practiced in the Rwamagasa area, the importation of geophagic materials into local markets from outside the contaminated region should be encouraged and the negative effects of using local soils conveyed though local women's groups and childhood development officers.

\section{Medical investigation methodology}

The extraction of the gold with liquid mercury releases Hg, especially highly toxic Hg vapour into the local environment. The health status of 211 volunteers in Rwamagasa artisanal gold mining area and 41 nonexposed people from a nearby control area in Katoro, located $30 \mathrm{~km}$ distant from Rwamagasa was assessed with a standardised health assessment protocol from UNIDO (UNIDO 2003) by an expert team from the University of Munich, Germany in October/November 2003. The health assessment protocol was developed by UNIDO in collaboration with the Institut für Rechtsmedizin der Ludwig-Maximilians-Universität München, Germany and other international experts. The "Health Assessment Questionnaire" was partly translated in Swahili to be used to examine the general health condition of members of the mining community and to indicate symptoms of $\mathrm{Hg}$ poisoning. State of the art anamnestic, clinical, neurological, neuro-psychological and toxicological tests were used. All participants were examined to identify neurological disturbances, like ataxia, tremor and coordination problems. The data was compiled for statistical purposes and confidentiality regarding all health related issues was maintained.

\section{Results of the medical investigation}

Mercury concentrations in the bio-monitors urine, blood and hair were significantly higher statistically in the exposed population from Rwamagasa compared with the Katoro control group, but only some amalgam burners showed Hg levels above the toxicological threshold limit HBM II in urine (Figure 4), blood and hair. A speciation of $\mathrm{Hg}$ in hair demonstrates that mainly inorganic $\mathrm{Hg}$ (including $\mathrm{Hg}$ vapour) contributes to the high body burden of the artisanal miners. Low mercury concentrations in all biomonitors (especially blood) of volunteers not occupationally exposed to mercury in Rwamagasa indicate that there is no relevant 
secondary exposure of humans to Hg in this area by air, drinking water or food, especially locally caught fish.

Only a few statistically significant correlations were detected between Hg concentrations in biomonitors (urine, blood and hair) and anamnestic/clinical data for the amalgam-burners sub-group. Significant correlations included those between the anamnestic data (i) "tremor at work" with Hg in urine, blood and total $\mathrm{Hg}$ in hair and (ii) $\mathrm{Hg}$ in blood with tiredness, lack of energy, weakness, and problems with concentration and clear thinking. The only significant correlation between a classical clinical indicator and $\mathrm{Hg}$ in biomonitors was "heel to knee tremor" with total Hg in hair whilst significant correlations with the "Matchbox test" were found with $\mathrm{Hg}$ in urine and blood. Whereas on a group basis $\mathrm{Hg}$ in the target tissue (i.e. brain) correlates well with $\mathrm{Hg}$ in urine, blood and hair of people with significantly different levels of occupational or environmental exposure, the poor correlations between classical clinical indicators of mercury intoxication and $\mathrm{Hg}$ in bio-indicators within the group of amalgam-burners in the present study probably reflects large inter-individual differences (i.e. an individual's biomonitor $\mathrm{Hg}$ level may not directly indicate their target tissue (brain) Hg burden). In an individual who has suffered from chronic exposure to $\mathrm{Hg}$, damage to the central nervous system may have occurred months or years before the biomonitor samples were analysed. Biomonitor data indicate an individual's recent body-burden whereas the clinical indicators probably indicate an individual's past or cumulative $\mathrm{Hg}$ burden. This would explain why the former occupationally exposed group shows a high median medical score whilst the group's biomonitor Hg levels are only slightly elevated. When the results of individual anamnestic, clinical and neurological tests are summed together, significant correlations exist (i) between $\mathrm{Hg}$ in urine and blood with the anamnestic score and (ii) between $\mathrm{Hg}$ in urine and the sum of all the anamnestic, clinical and neurological tests. It was shown that for the Rwamagasa amalgam-burner group, which is predominantly exposed to inorganic $\mathrm{Hg}$ (including $\mathrm{Hg}$ vapour), the Hg concentration in urine is a sound predictor for a Hg intoxication.

Typical symptoms of Hg intoxication were prevalent in the exposed group. For example, combining the medical score with the biomonitoring results made it possible to diagnose chronic $\mathrm{Hg}$ intoxication in 25 out of 99 amalgam burners, and in 3 out of 15 former amalgam burners (Figure 5). Table 1 shows the Hg concentrations in biomonitors for the group of intoxicated amalgam burners.

Table 1: Mercury concentrations in biomonitors of the 25 intoxicated amalgam burners (in some cases hair samples were not available)

\begin{tabular}{lcccc}
\hline & $\begin{array}{c}\text { Hg-blood } \\
(\mu \mathrm{g} / \mathrm{l})\end{array}$ & $\begin{array}{c}\text { Hg-Urine } \\
(\mu \mathrm{g} / \mathrm{g} \text { crea. })\end{array}$ & $\begin{array}{c}\text { T-Hg-Hair } \\
(\mu \mathrm{g} / \mathrm{g})\end{array}$ & $\begin{array}{c}\text { MeHg-Hair } \\
(\mu \mathrm{g} / \mathrm{g})\end{array}$ \\
\hline $\mathrm{N}$ & 25 & 25 & 20 & 18 \\
median & 8.6 & 13.2 & 4.1 & 0.77 \\
maximum & 33.3 & 36.8 & 48.7 & 5.25 \\
\hline
\end{tabular}




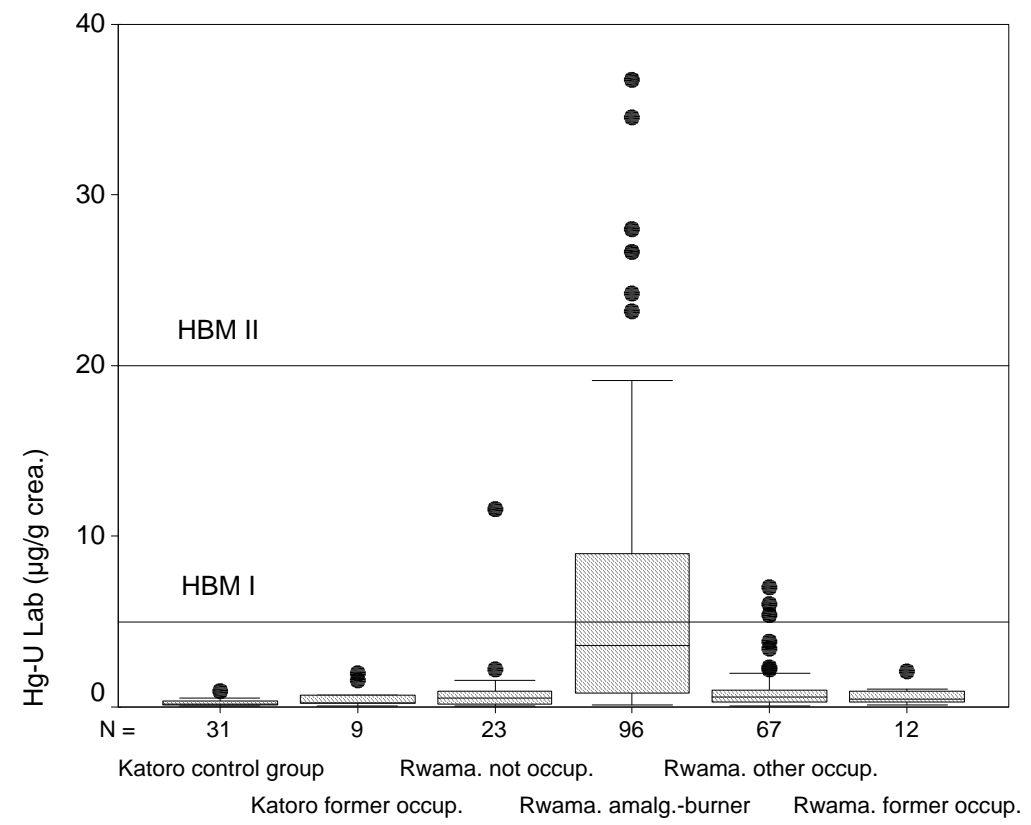

Figure 4. Total mercury concentration in urine ( $\mu \mathrm{g} \mathrm{Hg/g}$ creatinine), determined in laboratory ( occup. = occupational)

Within the other population groups in Rwamagasa (i.e. people not occupationally exposed to $\mathrm{Hg}$ ) and in the Katoro control group no cases of Hg intoxication were diagnosed. The percentage of cases diagnosed with Hg intoxication within the amalgam burners was lower in Rwamagasa than in the comparable small-scale gold mining area of Mt. Diwata in the Philippines, for example, where $85 \%$ of the amalgam burners were intoxicated (Drasch 2001). The difference in the level of intoxication cannot be explained by a different (i.e. a safer) amalgam burning technique in Rwamagasa. Moreover, it must kept in mind, that the maximal burden (as expressed in the top $\mathrm{Hg}$ concentrations found in the biomonitors) was comparable to Mt. Diwata. The impression gained during the field programme was that this difference might be explained just by a lower amount of $\mathrm{Hg}$ used for gold extraction in the Rwamagasa area, reflecting the lower level of gold production. This results in a lower number people exhibiting high levels of Hg intoxication.

Diagnosis: Mercury Intoxication

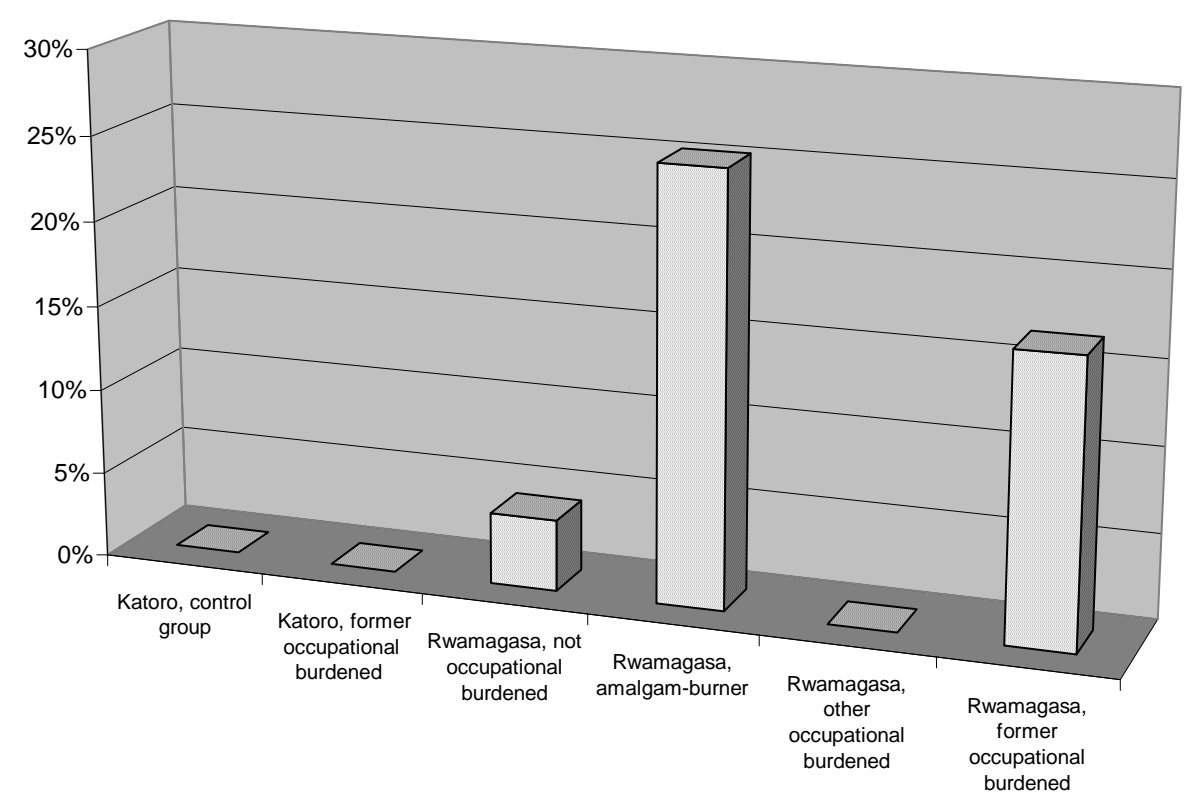


Figure 5. Frequency of the diagnosis of mercury intoxication in the different sub-groups.

Child labour in the Rwamagasa mining sites is very common from the age of 10 . The children work and play with their bare hands with Hg. This is very important because Hg can cause severe damage to the developing brain.

Nursed babies of amalgam burning mothers are at special risk. Extremely high mercury concentrations were detected in two out of five breast-milk samples from nursing mothers who worked as amalgam burners. In addition to a placental transfer of $\mathrm{Hg}$ during pregnancy from the mother to the foetus (as has been proved in other studies) this high Hg burden of nursed babies should be a cause of great concern.

Poverty is the main reason for the poor health status of the small-scale mining communities. Struggling for survival frequently makes gold mining a necessity in order to obtain financial resources. The daily fight for survival makes the miners put their own health and the health of their children at risk.

A reduction of the release of Hg vapours from small-scale gold mining like in Tanzania into the atmosphere should not only reduce the number of $\mathrm{Hg}$ intoxicated people in the mining area but it will also reduce global atmospheric pollution, because a significant proportion of mercury vapours formed by burning of amalgam in the open-air may be transported long-range distances (Lamborg, 2002). The total (global) release of mercury vapour from artisanal gold mining is currently estimated to be up to 1,000 metric tonnes per year (MMSD, 2002), while approximately 1.900 tonnes of $\mathrm{Hg}$ from all other anthropogenic sources were released into the atmosphere (Pirrone, 2001).

Mercury is undoubtedly a serious health hazard in the small-scale gold mining area of Rwamagasa. Working for many years in the amalgamation process, especially amalgam burning has resulted in severe symptoms of $\mathrm{Hg}$ intoxication. The exposure of the whole community to Hg is reflected in raised Hg levels in the urine, and the detection of the first symptoms of brain damage such as ataxia, tremor and movement disorders. Mercury intoxication (according to the definition of UNIDO (UNIDO 2003)) was diagnosed in 25\% of the amalgam burners from Rwamagasa. In addition, intoxication was also detected in some people that had formerly worked with Hg and amalgam. People from Rwamagasa who are not directly involved in amalgam burning, have a higher Hg burden than the control group, although the majority of these people are not intoxicated. The background $\mathrm{Hg}$ burden in the Katoro control group is the same order of magnitude as in western industrial countries.

\section{Recommendations for monitoring water quality and biota}

Monitoring is expensive and costs can be reduced if the main exposure routes are known. Hence there is a need for a more intensive study to link exposures from various pathways to Hg levels in blood prior to the development of monitoring or remediation strategies.

Monitoring in the environmental survey followed, as closely as was practicable, the internationally accepted protocols recommended by UNIDO (2003). It is recommended that water monitoring be carried out in the Rwamagasa drainage system during the wet season in order to test for $\mathrm{Hg}$ dispersion in solution and in the suspended sediment. The short term and medium term temporal variation in these pollution indicators should also be investigated.

Continuous monitoring equipment capable of determining $\mathrm{Hg}$ at low concentrations in drainage systems is, as far as the authors of this report are aware, not available commercially. So any monitoring system would be periodic rather than continuous. Quarterly monitoring will probably be adequate for the Isingile and Nikonga Rivers for a period of two years. If no significant $\mathrm{Hg}$ concentrations are detected during that period, and there are no significant changes in the amount of mineral processing and associated factors, then annual monitoring, following the USEPA recommendations, will probably be adequate.

The only effective option to prevent continuing $\mathrm{Hg}$ pollution of the Isingile River and surrounding agricultural areas is to require (a) the removal of all the existing mineral processing waste currently located close to the Isingile River and (b) the termination of all mineral processing activities in the vicinity.

Monitoring of drinking water from wells in the Rwamagasa area was not carried out during the current survey, but should be considered when designing any future water quality monitoring systems. 
Monitoring of biota (fish and agricultural crops) has been carried out as part of the current study and could be carried out periodically using the UNIDO sampling protocols (UNIDO, 2003), which document procedures for the periodic monitoring of aquatic biota. Periodic monitoring of agricultural crops could also be carried out, although the results of this study indicate that little Hg is present in most of the crops. Due to time and funding constraints, the current study was able to sample only a relatively limited number of sites. For this reason it is recommended that a more comprehensive survey should be carried out, in order to verify the results presented in this study.

\section{Recommendations for remediation and rehabilitation}

The present survey did not detect any concentrations of $\mathrm{Hg}$ in solution that would require remediation, as they did not exceed water quality standards. Should future water quality monitoring detect concentrations that require remediation, then a number of remediation technologies may be appropriate.

From a practical point of view, there would be little justification in trying to remediate and rehabilitate the Hg contaminated bottom sediments of the Isingile River until (i) the releases of Hg contaminated mineral processing tailings from the Rwamagasa area have been terminated, and (ii) the risk of future contamination of the drainage system by progressive or catastrophic releases of $\mathrm{Hg}$ contaminated processing waste has been eradicated. It is, however, relatively unlikely that the tailings piles located adjacent and to the south of the Isingile are a potential source of catastrophic contamination as the waste piles are relatively small and the slopes are relatively gentle. However, both (i) the highly contaminated amalgamation pond tailings and (ii) the primary and sluice box tailings, that have been contaminated with $\mathrm{Hg}$ as a result of reprocessing the amalgamation pond tailings, are probably the main source of potential $\mathrm{Hg}$ contamination in the Rwamagasa area and dispersal of these tailings needs to be avoided. Removal of the tailings to a safe containment facility, underlain and covered with lateritic material (hydrous ferric oxides) should be considered. As far as the authors are aware, no clean-up goals for Hg have been set in Tanzania, although this needs to be verified.

The principal remediation-rehabilitation options for Hg-contaminated soils and sediments in the Isingile River - Rwamagasa area include (i) excavation of Hg-contaminated soil and disposal to an off-site secure landfill or depository, (ii) electroleaching, comprising wet extraction followed by electrolytic preparation of the leachate, an emerging and potential alternative cleanup method that is reported to offer a cheaper and more environmentally friendly alternative to thermal treatment or the acid leaching process. The cost of these potential remediation options has not been estimated.

Specific practical remediation measures cannot be recommended until a much more detailed assessment has been made of $\mathrm{Hg}$ concentrations in the agricultural soils, their uptake by crops and transfer into the human food chain. On the basis of evidence collected during this survey, it appears that significant amounts of Hg are not adsorbed into the grain of the agricultural plants. If this can be confirmed by more detailed site specific studies (involving further collection and analysis of soil and rice grain samples from exactly the same sites, for example) it may be possible to confirm that there is little or no potential for a direct negative impact on human health caused by the consumption of rice and other crops grown on these relatively high $\mathrm{Hg}$ soils. Mercury uptake by other crops (such as maize or cassava) grown on soils that are currently used for rice should also be evaluated in case such a change in agricultural practices would increase the potential exposure of the local population.

\section{Recommendations for reduction of the release of mercury into the environment}

The exposure to $\mathrm{Hg}$ for the miners and the community has to be drastically decreased. Proper mining techniques to reduce the accidents and $\mathrm{Hg}$ exposure are essential. Small-scale miners need all possible support to introduce cleaner and safer gold mining and extraction technologies.

The Local Mines Office in Geita needs to ensure that the small scale miners follow relevant mining and environmental regulations and approved practices, such as making sure that all amalgamation is carried out in cemented ponds and that all tailings from these amalgamation ponds are stored in appropriate cemented storage areas that prevent dispersal of $\mathrm{Hg}$ onto adjacent land and into water courses.

Exposure to $\mathrm{Hg}$ vapour is avoidable with the application of simple technological improvements such as retorts. Technical solutions need to go hand in hand with awareness raising campaigns. 
An alliance of local, regional, governmental and intergovernmental bodies is needed to improve the social, health and environmental situation of artisanal small-scale gold miners. Cooperation between health and environmental sectors is needed on local, regional, national and intergovernmental level; for example, UNIDO and WHO in Dar es Salaam could form a nucleus of a national mercury task force.

\section{Recommendations for reduction of mercury as a health hazard}

The clinical testing and laboratory results indicate that $\mathrm{Hg}$ is a major health hazard in the Rwamagasa area especially for those artisanal miners who burn amalgam. A lower, but significant, level of Hg intoxication is observed in those residents of Rwamagasa who have no occupational exposure.

In order to reduce the level of risk from $\mathrm{Hg}$ it is suggested that:

1. Child labour with highly toxic substances must be stopped immediately. Legal restrictions on child labour need to be implemented immediately.

2. Women of childbearing age need special information campaigns on the risk of $\mathrm{Hg}$ to the foetus and the nursed baby and advice on how to avoid, or at least reduce, exposure.

3. Participants in the medical assessment diagnosed with Hg intoxication need medical treatment. A system is required for the diagnosis and treatment of Hg related health-problems. Capacity building, including establishing laboratory facilities to analyse $\mathrm{Hg}$ in human specimens is required. The financial aspect of treatment and the legal problem of importing drugs (such as chelating agents like DMPS or DMSA, required to remove Hg from the body) need to be solved. Funding of preventive campaigns and for treatment facilities is now needed.

4. Training programs for the health care providers in the district in Geita and other health centres in mining areas is required to raise awareness of $\mathrm{Hg}$ as a health hazard and advise people how they can reduce their own and their children's environmental and occupational exposure to $\mathrm{Hg}$.

5. Clinical training of local health workers, including the use of a standardised questionnaire and examination flow scheme (MES = mercury examination score). Particular attention needs to be paid to collecting information on individual's environmental and occupational exposure as this will aid the detailed assessment of exposure routes and the design of strategies that will help to reduce $\mathrm{Hg}$ exposure.

6. A mobile "mercury ambulance" might ensure that small-scale miners can be reached more efficiently than from a permanent local health office. A "mercury ambulance" equipped with the necessary medical and laboratory utensils bus could be driven into the artisanal mining areas. Two or three specially trained doctors or nurses could perform the examinations, and begin to carry out treatment. The ambulance could also be used for health awareness programs (e.g. video equipment). Miners in remote areas might welcome evening entertainment and soccer videos might attract more miners to the "mercury ambulance", than other information material. Sponsors could be sought for a "mercury ambulance", which could be based on a truck or bus chassis.

\section{Recommendations to increase awareness of the risks of mercury}

(a) Assess in a different study design the possibility of $\mathrm{Hg}$ related birth and growth defects, increased abortion/miscarriage rates, infertility problems, learning difficulties in childhood or other neuropsychological problems related to occupational and/or environmental mercury exposure.

(b) Assess in a more detailed study the possible transfer of Hg from the environment to, mother to child via breast-milk and related possible adverse health effects. Females at childbearing age and younger urgently require more awareness to refrain from amalgam burning, at least during pregnancy and nursing. If this is not possible, a discussion whether to provide them with milk powder and high purity drinking water together with training them to prepare hygienically appropriate formula food for their babies needs to be based on a larger data base and a different epidemiological approach.

(c) Assess the relative importance of the main potential sources of exposure for people in Rwamagasa who are not occupationally exposed to $\mathrm{Hg}$ (i.e. airborne Hg-vapour; ingestion of $\mathrm{Hg}$-contaminated dust through hand-to-mouth contact or on unwashed or inadequately washed food; ingestion of locally grown Hg- 
contaminated crops; Hg-contaminated fish from local streams; deliberate occasional or habitual consumption of soil (geophagia)). This has not been evaluated adequately and requires further integrated investigations by a team of environmental, public health, medical and toxicological specialists.

\section{Recommendations for improvement of general health.}

Poverty is considered to be the main reason for most of the health and environmental problems in the Rwamagasa area. At the moment it does not seem to be acceptable that children live in Rwamagasa because of inadequate sanitary standards and high exposure to $\mathrm{Hg}$. The improvement of sanitary standards is needed urgently.

The relative occupational health risks of mining should be assessed in more detail (accidents, malaria, drinking water quality, sexually transmitted diseases, tuberculosis, HIV / AIDS). One option to reduce the health hazards in Rwamagasa might be a proper zoning into industrial areas, commercial areas and housing areas. The imposition of basic hygienic standards, such as proper drinking water and reduction of Anopheles mosquitoes would also lead to an improvement in the health of the local people. Raising safety awareness and the introduction of appropriate mining techniques (such as better tunnel safety) will help to reduce the risk of accidents at mining sites. The risk of sexually transmitted diseases could be reduced if campaigns for safer sex were more effective. An appropriate health service is urgently required to improve the health status of the Rwamagasa community.

\section{References}

Appel, P.W.U. et al., 2000. An integrated approach to mineral exploration and environmental assessment in southern and eastern Africa - a pilot study in Tanzania. 2000/16, Danmarks og Grønlands Geologiske Undersøgelse.

Appleton JD, Taylor H, Lister TR, Smith B, Drasch G, Boese-O’Reilly S, 2004. Final report for an assessment of the environment and health in the Rwamagasa area, Tanzania. UNIDO Project EG/GLO/01/G34. British Geological Survey Commissioned Report CR/04/129.

Asano, S. et al., 2000. Acute inorganic mercury vapor inhalation poisoning. Pathology International, 50(3): 169-174.

Campbell, L. M., D. G. Dixon, et al. 2003a. A review of mercury in Lake Victoria, East Africa: Implications for human and ecosystem health. Journal of Toxicology and Environmental Health, Part B-Critical Reviews 6(4): 325-356.

Campbell, L. M., O. Osano, et al. 2003b. Mercury in fish from three rift valley lakes (Turkana, Naivasha and Baringo), Kenya, East Africa. Environmental Pollution 125(2): 281-286.

Drasch G, Boese-O’Reilly S, Beinhoff C, Roider G, Maydl S. 2001. The Mt. Diwata study on the Philippines 1999 - assessing mercury intoxication of the population by small scale gold mining. Science of the Total Environment 267, 151-168

Harada, M., S. Nakachi, et al. 1999. Monitoring of mercury pollution in Tanzania: relation between head hair mercury and health. Science of the Total Environment. 227(2-3): 249-256.

Ikingura and Akagi 2002. Proceedings of the International Workshop on Health and Environmental Effects of Mercury, Impacts of Mercury from Artisanal Gold Mining in Africa. University of Dar es Salaam, 19-20 November 2002. 56-65.

Ikingura, J. R. and H. Akagi. 1996. Monitoring of fish and human exposure to mercury due to gold mining in the Lake Victoria goldfields, Tanzania. Science of the Total Environment 191(1-2): 59-68.

Ikingura, J.R., Mutakyahwa, M.K.D. and Kahatano, J.M.J., 1997. Mercury and mining in Africa with special reference to Tanzania. Water Air and Soil Pollution, 97(3-4): 223-232.

Kahatano et al 1997. Study of Mercury Levels in Fish and Humans in Mwakitolyo Mine and Mwanza Town in the Lake Victoria Goldfields, Tanzania. In Landner L (ed) 1997. Small Scale Mining in African Countries. Prospects, Policy and Environmental Impacts. 159-170.

Kinabo, C. and Lyimo, E., 2002. Preliminary studies of mercury contamination in various food crops at Mgusu mining village in Geita, Tanzania, Proceedings of the International Workshop on Health and Environmental Effects of Mercury - Impacts of Mercury from Artisanal Gold Mining in Africa. National Institute for Minamata Disease, Japan \& University of Dar es Salaam, Tanzania, University of Dar es Salaam, Tanzania, pp. 204-214.

Kinabo, C., 1996. Mercury pollution associated with artisanal mining on Lake Victoria Goldfield, in Tanzania. In: R. Ebinghaus, G. Petersen and U. von Tuempling (Editors), Fourth international conference on mercury as a global pollutant; book of abstracts. GKSSForschungszentrum, Geesthacht, Federal Republic of Germany, pp. 335.

Kinabo, C., 2002a. Comparative analyses of Hg-concentration in domestic ducks (Anser sp.) from Mgusu mining village in Geita, Mwanza and Dar es Salaam, Proceedings of the International Workshop on Health and Environmental Effects of Mercury - Impacts of Mercury from Artisanal Gold Mining in Africa. National Institute for Minamata Disease, Japan \& University of Dar es Salaam, Tanzania, University of Dar es Salaam, Tanzania, pp. 215-222. 
Kinabo, C.P., 2002b. Comparative analyses of mercury contents in cosmetics and soaps used in the city of Dar es Salaam, Proceedings of the International Workshop on Health and Environmental Effects of Mercury - Impacts of Mercury from Artisanal Gold Mining in Africa. National Institute for Minamata Disease, Japan \& University of Dar es Salaam, Tanzania, pp. 173-186.

Kishe, M.A. and Machiwa, J.F., 2003. Distribution of heavy metals in sediments of Mwanza Gulf of Lake Victoria, Tanzania. Environment International, 28(7): 619-625.

Lamborg CH, Fitzgerald WF, O’Donnell J, Torgersen T. 2002 A non-steady-state compartment model of global-scale mercury biogeochemistry with interhemispheric gradients. Geochim Cosmochim Acta 66:1105-1118.

Machiwa, JF, Kishe, MA, Mbilinyi HG, Mdamo A and Mnyanza O. 2003. Impact of gold mining in Lake Victoria Basin on mercury levels in the environment. Lake Victoria Environmental Management Project Report. 46pp.

MMSD, 2002. Breaking New Ground: Mining, Minerals, and Sustainable Development. International Institute for Environment and Development. Earthscan Publications Ltd, London, UK. As available at http://www.iied.org/mmsd/finalreport/index.html per September 2002.

Mutakyahwa, M.K.D., 2002. Mercury contamination due to gold mining in Tanzania, Proceedings of the International Workshop on Health and Environmental Effects of Mercury - Impacts of Mercury from Artisanal Gold Mining in Africa. National Institute for Minamata Disease, Japan \& University of Dar es Salaam, Tanzania, pp. 21-29.

Pirrone N, Munthe J, Barregård L, Ehrlich HC, Petersen G, Fernandez R, Hansen JC, Grandjean P, Horvat M, Steinnes E, Ahrens R, Pacyna JM, Borowiak A, Boffetta P, Wichmann-Fiebig M. 2001. Ambient Air Pollution by Mercury (Hg) - Position Paper. Office for Official Publications of the EC. (available on http://europa.eu.int/comm/environment/air/background.htm\#mercury).

Semu, E., Guttormsen, D. and Bakken, L., 1989. Microbial-Populations and Activity in 2 Soils of Tanzania as Influenced by Mercury. Mircen-Journal of Applied Microbiology and Biotechnology, 5(4): 533-542.

Sindayigaya, E., Van Cauwenbergh, R., Robberecht, H. and Deelstra, H., 1994. Copper, zinc, manganese, iron, lead, cadmium, mercury and arsenic in fish from Lake Tanganyika, Burundi. The Science of The Total Environment, 144(1-3): 103-115.

UNIDO, 2003. Protocols for Environmental and Health Assessment of Mercury Released by Artisanal and Small-Scale Gold Miners. UNIDO, Vienna.

University of Dar es Salaam, 1994. Monitoring of mercury and other heavy metal pollution in gold mining areas around lake Victoria, Tanzania. Final report, Department of Geology, University of Dar es Salaam, Dar es Salaam. 55 pp.

van Straaten, P., 2000. Human exposure to mercury due to small scale gold mining in northern Tanzania. Science of the Total Environment, 259(1-3): 45-53.

van Straaten, P., 2000. Mercury contamination associated with small-scale gold mining in Tanzania and Zimbabwe. Science of the Total Environment, 259(1-3): 105-113. 